\title{
DOENÇA CRÔNICA DA CRIANÇA: NECESSIDADES FAMILIARES E A RELAÇÃO COM A ESTRATÉGIA SAÚDE DA FAMÍLIA
}

\author{
Eliane Aparecida de Oliveira COSTA ${ }^{\mathrm{a}}$, Giselle DUPAS ${ }^{\mathrm{b}}$, \\ Etelvaldo Francisco Rego SOUSA ${ }^{\mathrm{c}}$, Monika WERNET ${ }^{\mathrm{d}}$
}

\section{RESUMO}

Este estudo objetivou conhecer a percepção da família sobre a relação com a Unidade Saúde da Família (USF) na vivência com a doença crônica da criança. Em um desenho qualitativo utilizou-se o Interacionismo Simbólico como sustentáculo teórico, a Pesquisa de Narrativa como método e entrevistas com as famílias como instrumento para a coleta de dados. Os dados foram coletados por entrevista semiestruturada, com 7 famílias de crianças com doença crônica, cadastradas em USFs de uma região com alto índice de vulnerabilidade social, de um município do interior paulista. Os resultados mostraram como a relação da família com a USF é influenciada por elementos da experiência e trajetória familiar e como a vivência da doença crônica da criança é fortemente marcada pela relação com os serviços de saúde. Tal situação tem grande influência sobre as respostas da família, o que exige um engajamento sistemático e comprometido do sistema de saúde no alívio do sofrimento familiar, para além do tratamento pontual da patologia.

Descritores: Família. Doença crônica. Criança. Programa Saúde da Família. Atenção primária à saúde.

\section{RESUMEN}

Este estudio tuvo como objetivo conocer la percepción de la familia sobre su relación con la Unidad de Salud de la Familia respecto a su vivencia con la situación de la enfermedad crónica del niño. El diseño cualitativo utilizado fue el Interaccionismo Simbólico como base teórica, la Investigación Narrativa como método y entrevistas con las familias como instrumentos de recopilación de datos. Los datos fueron recolectados a través de entrevistas semiestructuradas con siete familias que tuvieron un hijo como miembro con una enfermedad crónica se matricularon en las Unidades de Salud de la Familia en una región con alta vulnerabilidad social, una ciudad de interior. Los resultados mostraron que la relación de la familia con la Unidad de Salud de la Familia está influenciada por elementos de la experiencia y del recorrido familiar, y la vivencia de la enfermedad crónica del niño es fuertemente marcada por la relación con los servicios de salud. Esta situación tiene una gran influencia en las respuestas de la familia, que requiere un compromiso sistemático y comprometido del sistema de salud para aliviar el sufrimiento de la familia, además de solicitar el tratamiento de la enfermedad.

Descriptores: Familia. Enfermedad crónica. Niño. Programa de Salud Familiar. Atención primaria de salud. Título: Enfermedad crónica del niño: necesidades familiares y su relación con la Estrategia Salud de la Familia.

\section{ABSTRACT}

The purpose of this study was to learn the perception that families of children with a chronic disease make of their relationships with the Family Health Unit (FHU). This qualitative study was performed using symbolic interactionism as the theoretical ground and narrative inquiry as the method. Data were collected through semi-structured interviews with seven families of children with chronic disease, enrolled in the FHU of a region with high social vulnerability, in São Paulo state, Brazil. Results showed that the family's relationship with the FHU is influenced by elements from their experience and trajectory, and that their experience as a family of a child with a chronic disease is strongly marked by their relationship with the health care services. This has great influence on the responses of the family, thus requiring a systematic and committed engagement of the health system in relieving their suffering, beyond merely treating the disease.

Descriptors: Family. Chronic disease. Child. Family Health Program. Primary health care.

Title: Children's chronic disease: family needs and their relationship with the Family Health Strategy.

\footnotetext{
a Enfermeira. Mestre em Enfermagem pelo Programa de Pós-Graduação em Enfermagem da Escola de Enfermagem da Universidade de São Paulo. São Paulo, SP, Brasil. eli.apoc@gmail.com

b Enfermeiro. Mestre em Enfermagem pelo Programa de Pós-Graduação em Enfermagem da Escola de Enfermagem da Universidade de São Paulo. São Paulo, SP, Brasil. etelsousa@gmail.com

c Enfermeira. Professora Adjunta do Departamento de Enfermagem da Universidade Federal de São Carlos. São Carlos, SP, Brasil. mwernet@ufscar.br

d Enfermeira. Professora Associada do Departamento de Enfermagem da Universidade Federal de São Carlos. São Carlos, SP, Brasil. gdupas@ufscar.br
} 


\section{INTRODUÇÃO}

Manter a saúde da família é uma exigência das mais importantes para a sobrevivência de uma sociedade. A literatura aponta ${ }^{(1-8)}$ a necessidade de considerar a família como unidade de cuidado, necessitando de olhar ampliado para suas necessidades de saúde, no sentido de uma visão sistêmica sobre o seu funcionamento e as suas relações intra e extra familiares.

As condições crônicas são responsáveis por $60 \%$ de todo o ônus decorrente de doenças no mundo. Estima-se para o ano de 2020 que $80 \%$ da carga de doença dos países em desenvolvimento deva advir de problemas crônicos ${ }^{(4)}$.

O Sistema Único de Saúde (SUS) brasileiro tem na Estratégia Saúde da Família (ESF) um modelo de atenção que se baseia na família, território e responsabilização ${ }^{(5)}$. Tomando-a como co-participante no processo de cuidar, vemos a ESF como uma possível articuladora na instrumentalização e apoio da unidade familiar para o enfrentamento da doença crônica da criança.

A qualidade do vínculo entre serviço de saúde - representado por seus profissionais - e família, constitui condição importante na prevenção de complicações e de (re)internações ${ }^{(6)}$, principalmente no seguimento ambulatorial e acompanhamento domiciliar, o que aponta para necessidade de estudos que contemplem esse contexto. Ao mesmo tempo, torna-se imprescindível lançar um olhar sobre a vivência da família com a doença e os processos que se impõem nesta experiência ${ }^{(7)}$, no intuito de conhecer seu funcionamento e respostas, procurando pensar em estratégias capazes de diminuir fatores que afetam negativamente a saúde da família.

Esta pesquisa objetivou conhecer como a família percebe a relação com a USF no processo de cronicidade infantil. Tal investigação vai ao encontro dos novos desafios que se impõem ao Sistema da Saúde Brasileiro no que diz respeito a como entender, enfrentar e gerenciar as mudanças nos padrões de ocorrência das doenças e sua relação com a família ${ }^{(8,9)}$.

\section{MÉTODO}

Trata-se de estudo qualitativo, que utilizou o Interacionismo Simbólico como lente teórica, por indicar que os significados construídos alteram-se nos contínuos processos interativos ${ }^{(10)}$. A pesquisa de narrativa com perspectiva holística e ênfase no conteúdo foi a estratégia metodológica escolhida para reconstruir os elementos significativos que traduzem a interação(11).

Os sujeitos foram famílias moradoras de uma cidade do interior paulista, atendidas por equipes da ESF, que contemplassem os seguintes critérios de inclusão: conviver em domicílio com criança(s) em situação de cronicidade, ser cadastrado na USF da região adscrita e ser indicado pelo ACS da unidade como usuário do serviço.

A coleta de dados se deu no domicílio de famílias adscritas ao território das USFs, selecionadas por terem grande contingente de população infantil e pertencerem a uma região com altos índices de vulnerabilidade social ${ }^{(12)}$.

Os critérios de exclusão compreenderam: a criança não ter doença crônica, não ser cadastrada e/ou usuária das USFs selecionadas e não ser indicada pelo ACS.

A coleta de dados ocorreu de Maio a Agosto de 2010 .

O contato com as USFs ocorreu após a aprovação do Comitê de Ética em Pesquisa com Seres Humanos na Universidade Federal de São Carlos, sob o parecer $n^{\circ} 452 / 2009$. A identificação e acesso às famílias foi mediado inicialmente pelo ACS responsável pela microárea a qual pertencia a família.

Todas as recomendações da Resolução n. ${ }^{\circ}$ 196/96 do Conselho Nacional da Saúde foram seguidas ${ }^{(13)}$. A entrevista foi a estratégia adotada para acessar as narrativas das famílias de crianças sobre a experiência de cuidado na situação de cronicidade ${ }^{(11)}$. Foram convidadas a narrarem suas experiências a partir das seguintes perguntas disparadoras "Como está sendo para a família de vocês conviver com a situação crônica do (a) (nome da criança)?”; e "Como a família percebe a participação da USF neste processo?”. Outras observações e questionamentos foram realizados na identificação da necessidade de ampliar descrições ou elucidar articulações dos aspectos narrados.

A partir da transcrição na íntegra das entrevistas, seguiu-se uma leitura inicial que teve como foco a identificação dos aspectos temporais narrados e ações exigidas da família e dos profissionais. Depois seguiram-se leituras mais densas em busca dos aspectos do contexto os quais possibilitavam o acesso aos significados atribuídos, causas 
e conseqüências dos fatos narrados, tradutores das preocupações, sofrimentos e aspirações dos entrevistados ${ }^{(11)}$.

\section{RESULTADOS E DISCUSSÃO}

Foram entrevistadas sete famílias que experienciavam a condição crônica de seus filhos no contex to do domicilio e que estavam recebendo o acompanhamento da USF de referência. A tabela 1 traz a caracterização geral das famílias do estudo e o tempo de adscrição à USF de referência.

$\mathrm{Na}$ lente interpretativa ${ }^{(10)}$ utilizada, o ser humano define e age na situação de acordo com significações construídas, que emergem na interação social e influem nas atitudes, formas organizatórias e relações intra e interpessoais estabelecidas. A análise dos dados possibilitou a identificação de 5 categorias baseadas na trajetória da família e relações estabelecidas com o sistema profissional de cuidados, apresentadas a seguir.

\section{Batendo em muitas portas}

O fenômeno da cronicidade torna a relação da família com o serviço de saúde intrínseca ao próprio existir da família, uma vez que o conviver com a doença crônica traz necessidades de recursos que estão fora do contexto interno da unidade familiar e que pela organização social vigente, pertencem à esfera dos serviços de saúde. Assim, esta experiência faz a família buscar a rede profissional de cuidado a fim de apoiá-la em suas demandas ${ }^{(3)}$. Quando a família encontra-se em situação de vulnerabilidade social, como foi o caso das entrevistadas, se vê altamente dependente do serviço público para atendê-las.

Em busca de apoio para o tratamento da doença de sua criança, a família encontra inúmeras dificuldades. As características que permeiam a doença e o adoecer da criança predispõe a família a uma peregrinação que tem como objetivo encontrar os significantes do cuidado e uma rede de apoio que lhe pareça confiável e responsiva.

Era super difícil quando a gente começou a buscar tratamento... A gente não sabia, por exemplo, nem os lugares de ir, como fazia... Além de ter aquele problema, de saber que é uma coisa grave, de ter um filho doente... não saber para onde ir! Levava aqui um médico dava um remédio, levava ali, outro médico dava outro remédio, um falava uma coisa, outro falava outra. [...] (Família I).

A família relata uma peregrinação:

Um dia eu levei ele no pronto socorro porque ele estava com febre. No atendimento, a médica disse: 'Vocêj já está tratando o sopro?' Eu olhei pra cara dela do tipo: 'que sopro?'... Daí a unidade lá [USF] estava sem médico e meu marido falou pra gente levar ele no consultório do médico. Esse médico passou um monte de exames e falou assim: 'O sopro com certeza ele tem e também acho que ele tá com uma bronquite' ... Aí eu consegui pelo SUS fazer os exames... Só que não deu tempo de ir no retorno da consulta, ele foi internado... O dextro estava em 570! Fui no hospital com ele, a médica já fez a internação e a transferência para a UTI. Ele saiu e passou com o endocrinologista que pediu todos os exames e confirmou que era diabetes tipo 1, diabetes infantil e lá ele fez outros exames e aí descobriu o tal sopro... (Família V).

Tabela 1 - Caracterização geral das famílias entrevistadas. São Carlos, SP, de maio a agosto de 2010.

\begin{tabular}{|c|c|c|c|c|c|c|c|}
\hline Caracterização & $\begin{array}{c}\text { Família } \\
\text { I }\end{array}$ & $\begin{array}{c}\text { Família } \\
\text { II }\end{array}$ & $\begin{array}{c}\text { Família } \\
\text { III }\end{array}$ & $\begin{array}{l}\text { Família } \\
\text { IV }\end{array}$ & $\begin{array}{c}\text { Família } \\
\text { V }\end{array}$ & $\begin{array}{c}\text { Família } \\
\text { VI }\end{array}$ & $\begin{array}{c}\text { Família } \\
\text { VII }\end{array}$ \\
\hline $\begin{array}{l}\text { Patologia da } \\
\text { Criança }\end{array}$ & $\begin{array}{l}\text { Síndrome } \\
\text { de Marfan }\end{array}$ & $\begin{array}{c}\text { Fenilceto- } \\
\text { núria }\end{array}$ & $\begin{array}{l}\text { Paralisia } \\
\text { Cerebral }\end{array}$ & Diabetes & Diabetes & $\begin{array}{l}\text { Paralisia } \\
\text { Cerebral }\end{array}$ & $\begin{array}{c}\text { Síndrome } \\
\text { Fetal } \\
\text { Alcoólica }\end{array}$ \\
\hline Idade da Criança & 10 anos & 5 anos & 11 anos & 10 anos & 3 anos & 7 anos & 2 anos \\
\hline $\begin{array}{l}\text { Tempo de } \\
\text { Diagnóstico }\end{array}$ & 6 anos & 5 anos & 10 anos & 6 anos & 11 meses & 6 anos & 2 anos \\
\hline $\begin{array}{l}\text { Tempo de } \\
\text { Adscrição da } \\
\text { Família à USF }\end{array}$ & 3 anos & 5 anos & 2 anos & 3 anos & 3 anos & 3 anos & 3 anos \\
\hline
\end{tabular}


Estudo australiano ${ }^{(7)}$ que analisou em profundidade os movimentos de retomada de equilíbrio de vida em famílias que experienciam a doença crônica, mostrou que as tentativas de alcançar equilíbrio foram seriamente prejudicadas por serviços fragmentados, o que corrobora com nossos achados.

\section{Sentindo as repercussões da vulnerabilidade social no cuidado à criança}

Dados sociais brasileiros ${ }^{(14)}$ mostram que as classes econômicas mais baixas estão mais expostas às doenças e agravos, possuem menor cobertura com intervenções preventivas, maior probabilidade de adoecer, menor resistência às doenças, pior acesso a serviços de saúde, menor qualidade da atenção recebida em serviços de atenção primária, menor probabilidade de receber tratamentos essenciais e menor acesso a serviços de nível secundário e terciário. O contexto social no qual este estudo foi realizado trouxe estas condições agravadas pela cronicidade da criança.

A família percebe impactos em sua qualidade de vida e experimenta a angustia do querer e não poder, ou seja, depara-se com as necessidades da criança, sensibiliza-se a elas e, diante da escassez de recursos financeiros e sociais, anseia por oferecer-lhe, se não a cura, uma maior qualidade de vida.

Eu penso muito no recurso, não tem dinheiro pra arrumar isso daí, pra melhorar esta situação [referindo-se a problemas odontológicos que o filho apresenta em função da doença crônica] (Família I).

[...] o que a gente queria era ter condições de, mesmo sabendo que de repente ele não... não venha a andar, dar uma vida melhor pra ele, que ele possa se locomover, mesmo de cadeira de rodas. Seria poder levar ele na escola todos os dias, levar ele na fisioterapia, na hidroginástica... [a família não tem transporte próprio e sofre com a precariedade do que é oferecido pela prefeitura] (Família III).

Estudo $^{(6)}$ que relaciona a fragilidade clínica e a vulnerabilidade social de crianças com necessidades especiais de saúde, refere que a despeito da existência de uma legislação que garanta os direitos da criança, o desconhecimento das famílias em relação a tais direitos se sobrepõe. Os achados do presente estudo revelam como a família é impactada pela vulnerabilidade social no conviver com a doença crônica da criança, o que explicita a necessidade de empoderamento legal e social dessas famílias, a fim de subsidiá-las no enfrentamento das necessidades que a doença traz e, portanto, no oferecimento de melhores condições de vida à criança ${ }^{(6)}$.

Ao mesmo tempo, a família depara-se com a não resolutividade e morosidade dos serviços de saúde, ressaltando que diante da escassez de recursos a dependência da família com relação ao serviço público de saúde se torna acentuada.

A coisa que mais me incomoda é não ter recurso para resolver e o poder público, a medicina de um modo geral, que a gente depende das coisas, é demorado, até resolver um problema... No caso mesmo dessa cirurgia [aneurisma de aorta], foram dois anos na fila de espera, se tivesse que morrer antes... e se tivesse dinheiro a cirurgia tinha sido feita em 1 ou 2 meses (Família I).

Há uma acentuação da vulnerabilidade e sofrimento, pois a doença da criança ameaça profundamente o senso de segurança e de competência da família, e muitas delas não conseguem se engajar sozinhas de forma ativa no processo de reestruturação e alívio do sofrimento ${ }^{(15)}$. Parte destas respostas familiares à condição clínica da criança depende do estágio de vida familiar, do impacto sobre cada membro $^{(16)}$, de seus recursos financeiros, da capacidade de identificar apoios, mobilizando recursos internos e externos, sendo que a literatura aponta que grupos colocados à prova da exclusão social estão enfraquecidos em sua capacidade de reação ${ }^{(17)}$.

\section{Comparando os serviços de saúde e reconhecendo a USF como apoio}

A família, ao percorrer o sistema de saúde, vai elaborando suas percepções sobre cada serviço ofertado e realizando comparações entre um e outro, tanto no que diz respeito às especificidades, suas potencialidades e deficiências, como no que tange a qualidade dos mesmos, do ponto de vista técnico e relacional. Ao experienciar os diversos serviços de saúde, percebe o cuidado prestado pela USF como diferenciado em relação aos outros, no que diz respeito à proximidade e interação através basicamente da figura do ACS e das visitas domiciliares.

O sistema deles é diferente, sei lá... Vem visitar... No caso tem uma menina aí, uma psicóloga, que veio aqui, mas porque as ACSs já vem aqui, eu não fui procurar ninguém (Família VI). 
Ao comparar o atendimento prestado pela USF com o de outros serviços de saúde, identifica qualidade superior, pois percebe que ao conhecer o histórico de saúde das famílias e de seus membros e acompanhar de perto os eventos da cronicidade, tem maiores chances de saber como está lidando com a situação e agir de acordo com as necessidades apresentadas, o que ela não identifica em outros serviços.

Na unidade [USF] é mais fácil, porque eles já sabem do seu problema, sabem com o que você tá lidando e lá não sei... Odeio ir lá naquele CEME [Serviço Especializado de Referência]! Eu vou porque eu não tenho outro jeito! (Família III).

Eu até levava ele no pronto atendimento que é até mais perto de casa, só que lá é uma briga pra conseguir uma consulta e lá tem até pediatra, tem até mais especialidades do que lá na unidade, mas a dificuldade para conseguir uma consulta é bem maior, tudo é mais complicado. Mas lá não, na USF elas já conhecem o meu filho, me conhecem, conhecem o problema que ele tem... (Família V).

Na vinculação com a USF de referência, a família compartilha necessidades, estabelece parcerias, e ao sentir o compromisso da equipe para o atendimento de necessidades e a preocupação dos mesmos para com o bem estar de seus membros, torna-se mais receptiva à equipe e reconhece-se apoiada por ela.

$A$ agente comunitária vinha em casa, que era a moça que fazia o atendimento [...] Então, esse vínculo com a família facilita, facilita bastante (Família V).

Elas [as ACSs] vem na casa da gente, elas perguntam, querem saber como é que ele está, eu acho que só o fato delas virem querer saber já é um apoio para família, porque seria pior se ninguém se interessasse em saber como é que ele tá (Família VII).

Na percepção da família, a USF age acelerando o processo de acesso à rede de serviços de saúde, uma vez que conhecendo sua realidade e necessidades, prioriza a resolução das demandas que a cronicidade impõe, mobilizando mais rapidamente recursos internos da equipe ou da rede de apoio.

[em outros serviços]... você tem que passar com uma enfermeira, para depois ela ver o seu caso, para depois ela ver como está, para depois te encaminhar para um pediatra ou para o médico que não conhece o problema que está se passando na sua família. Lá [USF] conhecem o meu filho, todo mundo já me conhece, sabe que eu quero alguma coisa, que eu estou precisando de alguma coisa [...] já é um passo a mais, eles já te conhecem, já sabem o problema que você tem (Família V).

Eles tiveram participação, a gente precisava fazer um tratamento dos dentes, quando ficaram sabendo que era por causa da cirurgia, arrumaram rapidinho, foi uma semana tava tudo arrumadinho, e tudo que a gente precisa deles eles atendem a necessidade.(Família I).

Eles no começo me ensinaram muito, também porque ela estudava na escola perto da USF, então, ela ia pra lá direto (Família IV).

$\mathrm{O}$ atendimento das necessidades familiares, frente à doença crônica da criança, passa por uma transformação da prática profissional que possibilite uma aproximação não apenas territorial, mas relacional entre quem oferece ou presta o serviço de quem o recebe ${ }^{(5,9)}$, de modo a promover compromisso, solidariedade e construção conjunta, família e profissionais, do vínculo necessário ao cuidado pleno $^{(18)}$, o que de algum modo é favorecido no cenário de cuidado da USF.

Para que a USF seja reconhecida como apoio pelas famílias, o processo de vinculação torna-se salutar, pois apesar das limitações do serviço, a interação é que promove confiança, referenciação e abre portas para a reflexão-ação da equipe em relação ao seu real potencial de ajuda/apoio às necessidades familiares diante da doença crônica da criança ${ }^{(18)}$. Neste estudo notou-se, que quando os membros familiares eram chamados pelo nome, e a criança conhecida pelo dia a dia de cuidado, é que a família reconhecia a equipe como referencial para suas necessidades.

\section{Identificando limitações da USF}

A ESF parece produzir efeito positivo e progressivo nas condições de saúde da população mais pobre $^{(5)}$. No contexto pesquisado identificamos elementos que levam a família a reconhecê-la com apoio e ao mesmo tempo confrontar-se com suas limitações no atendimento das demandas familiares.

A família ao ser acompanhada pela USF aproxima-se do serviço e torna-se capaz de identificar seus limites, sejam eles impostos pela estruturação, pela relação dele com a rede de serviços e definição do seu papel no sistema de saúde, ou mesmo pelo padrão interacional estabelecido, ou seja, pela vinculação da família à USF por meio de seus profissionais. 
É lógico que eles não têm assim um recurso para todo o tratamento do caso dele, eles não tem estrutura, eles tem vontade, mas não tem estrutura $[\ldots]$ (Família I).

Eles também não tem muito recurso [...] Existe até um negócio de fisioterapia [residente em fisioterapia], só que esse tipo de fisioterapia que eles fazem... Eles vão até a casa da pessoa quando a pessoa não pode sair de casa, no caso a gente pode, tem cadeira e tal e é muita gente pra pouco fisioterapeuta... Então, só tem uma menina [residente de fisioterapia] e não dá conta, não dá conta. São muitos deficientes que tem aqui, de todos os tipos de deficientes... (Família III).

O cuidar e agir pautado nas necessidades de saúde da família exige também a premissa de que qualquer serviço ou programa de saúde deve guardar relação direta com as expectativas e valores da população usuária ${ }^{(9)}$. As USFs abordadas neste estudo se revelaram por vezes limitadas nesta capacidade, pois as necessidades advindas da cronicidade exigem uma ação ampla, e mesmo a proximidade territorial da USF não é suficiente para atender às necessidades quando não conectada e resguardada por ações intersetoriais e multiprofissionais, dentro de uma grande rede social ${ }^{(3,19)}$.

\section{CONCLUSÃO}

O desenvolvimento deste estudo possibilitou captar a percepção da família sobre sua relação com a USF de referência. Para além disso, os dados revelaram também a percepção das famílias com relação aos serviços de saúde como um todo, e como a experiência da família na vivência da doença crônica da criança é fortemente marcada pela relação com os serviços de saúde.

Nesse sentido, foi possível identificar que a percepção da família em relação à USF é atrelada a sua trajetória, ao curso da doença e ao processo de vinculação em meio ao que a família esteve e/ou está a viver, o que determina, inclusive, o sentir-se ou não apoiada.

A estruturação da atenção básica brasileira e a definição do papel da ESF prevêem uma fluidez de demandas de saúde por diferentes níveis de atenção. Ocorre que, na prática, a família necessita de apoio para realizar este transito pelo sistema de saúde, bem como de um serviço que, apesar de todas as especificidades e fragmentações de atendimento, lhe seja referência mais ampla, concreta e duradoura no enfrentamento da cronicidade, o que está potencialmente no papel da USF.
As vozes familiares, aqui apresentadas, revelam que a experiência da família no contexto de vulnerabilidade social traz a necessidade de rompimento com o ciclo dependência - não resolutividade - sofrimento familiar, no sentido de que o setor saúde como um todo, assuma sua participação na responsabilidade de transformação social, à luz de princípios como a integralidade e a equidade, previstos no SUS e planejados para serem viabilizados pela ESF.

Ao mesmo tempo em que o estudo possibilitou respostas também nos conduziu a novos questionamentos sobre a intervenção com família na situação de doença crônica e sofrimento, visto que os resultados evidenciaram que este aspecto não é um componente sistemático e explicito do papel do profissional, e que desse modo, em muitas situações o alívio do sofrimento ou alcance de bem-estar ocorre pelos próprios esforços da família.

A trajetória de cuidado percorrida pelas famílias entrevistadas expressa sofrimento, luta e desafio frente aos acontecimentos, o que impactou e impacta na dinâmica e no bem estar familiar, e que a USF é considerada pela família um avanço, mas ainda com limitações.

Em termos de limitação do estudo, temos a captação das famílias como um elemento, pois nas unidades do município há falta de um sistema de informação com registros claros. A identificação e o acesso às famílias com crianças doentes crônicas ficava limitado a referência dos profissionais, o ACS, figura que tem por característica conhecer o território e acessar com frequências as famílias. Mas a percepção daquelas que não são por eles reconhecidas ou evidenciadas, pode ser outra que necessita ser conhecida, e que para tanto requer uma identificação, cadastro e manutenção de dados referentes às famílias nesta condição que possa ser facilmente acessado.

\section{REFERÊNCIAS}

1 Mitra S, Banerjee S. The impact of pediatric nephrotic syndrome on families. Pediatr Nephrol. 2011;26(8):1235-40.

2 Christian BJ. Research commentary-challenges for parents and families: demands of caregiving of children with chronic conditions. J Pediatr Nurs. 2010;25(4):299-301.

3 Paula ES, Nascimento LC, Rocha SMM. The influence of social support on strengthening families 
of children with chronic renal failure. Rev Latinoam Enferm. 2008;16(4):692-9.

4. World Health Organization. Global status report on noncommunicable diseases 2010 [Internet]. World Health Organization; 2011 [cited 2011 Jul 11]. Available from: http://www.who.int/nmh/publications/ ncd_report2010/en/.

5 Fernandes LC, Bertoldi AD, Barros AJD. Utilização dos serviços de saúde pela população coberta pela Estratégia de Saúde da Família. Rev Saude Publica. 2009;43(4):595-603.

6 Neves ET, Cabral IE. A fragilidade clínica e a vulnerabilidade social das crianças com necessidades especiais de saúde. Rev Gaúcha Enferm. 2008;29(2):182-90.

7 Jeon YH, Jowsey T, Yen L, Glasgow NJ, Essue B, Kljakovic $\mathrm{M}$, et al. Achieving a balanced life in the face of chronic illness. Aust J Prim Health. 2010;16(1):66-74.

8 Ministério da Saúde (BR). Diretrizes e recomendações para o cuidado integral de doenças crônicas não-transmissíveis: promoção da saúde, vigilância, prevenção e assistência. Brasília (DF): MS; 2008.

9 Cecílio LCO. As necessidades de saúde como conceito estruturante na luta pela integralidade e eqüidade na atenção em saúde. In: Pinheiro R, Mattos RA. Os sentidos da integralidade na atenção e no cuidado à saúde. $6^{\mathrm{a}}$ ed. Rio de Janeiro: IMS/UERJ - CEPESC - ABRASCO; 2009. p. 113-126.

10 Blumer H. Symbolic interactionism: perspective and method. Englewood Cliffs: Prentice Hall; 1969.

11 Lieblich A, Tuval-Mashiach R, Zilber T. Narrative research: reading, analysis and interpretation. Applied social research methods. Thousand Oaks: SAGE. 1998. p.47.

\footnotetext{
Endereço do autor / Dirección del autor / Author's address

Eliane Aparecida de Oliveira Costa

Rua Caramboleira, 15, Cidade das Flores

06184-250, Osasco, SP

E-mail:eli.apoc@gmail.com
}

12 Fundação SEADE [Internet]. São Paulo: SEADE. [atualizado 2013 Jun 10, citado 2013 Jun 10] Índice Paulista de Vulnerabilidade Social - IPVS. Espaços e dimensões da pobreza nos municípios do Estado de São Paulo. Disponível em: htpp://www.seade.gov.br/ produtos/ipvs/pdf/oipvs.

13 Ministério da Saúde (BR), Conselho Nacional de Saúde. Resolução 196, de 10 de outubro de 1996: diretrizes e normas regulamentadoras de pesquisa envolvendo seres humanos [Internet]. Brasília (DF); 1996 [citado 2013 Jun 10]. Disponível em: http:// conselho.saude.gov.br/comissao/conep/resolucao. html.

14 Instituto Brasileiro de Geografia e Estatística. Síntese dos Indicadores Sociais: uma analise das condições de vida da população Brasileira: IBGE. Rio de Janeiro (RJ); 2007.

15 Marcon SS, Sassá AH, Soares NTI, Molina RCM. Dificuldades e conflitos enfrentados pela família no cuidado cotidiano a uma criança com doença crônica. Cienc Cuid Saude. 2007;6(Supl.2):411-419.

16 Wollenhaupt J, Rodgers B, Sawin KJ. Family management of a chronic health condition: perspectives of adolescent. J Fam Nurs. 2012;18(1):65-90.

17 Fracolli RA, Angelo M. A experiência da família que possui uma criança dependente de tecnologia. REME Rev Min Enferm. 2006;10:125-131.

18 Wernet M, Angelo M. Mobilizando-se para a família: dando um novo sentido à família e ao cuidar. Rev Esc Enferm USP. 2003;37(1):19-25.

19 Silva RVGO. Ramos FRS. O trabalho de enfermagem na alta de crianças hospitalizadas: articulação da atenção hospitalar e básica. Rev Gaucha Enferm. 2011;32(2):309-15.

Recebido em: 10.07.2012

Aprovado em: 13.08.2013 